\title{
Formation of silicon carbide nanowire on insulator through direct wet oxidation
}

\author{
Hoang-Phuong Phan ${ }^{\mathrm{a}}$, Ina Ginosuke ${ }^{\mathrm{b}}$, Toan Dinh ${ }^{\mathrm{a}}$, Takahiro Kozeki ${ }^{\mathrm{b}}$, Tuan-Khoa Nguyen ${ }^{\mathrm{a}}$, \\ Takahiro Namazuc ${ }^{c}$, Afzaal Qamar ${ }^{\mathrm{a}}$, Dzung Viet Dao ${ }^{\mathrm{a}}$, Nam-Trung Nguyen ${ }^{\mathrm{a}}$ \\ ${ }^{a}$ Queensland Micro- and Nanotechnology Centre, Griffith University, Queensland, Australia. \\ ${ }^{b}$ Department of Mechanical Engineering, University of Hyogo, Hyogo, Japan. \\ ${ }^{c}$ Department of Mechanical Engineering, Aichi Institute of Technology, Toyota, Japan.
}

\begin{abstract}
Silicon carbide on insulator is a promising platform for electronic devices at high temperature as well as for opto-electrical applications. Utilizing the chemical inertness of $\mathrm{SiC}$, this work presents a novel technique to form cubic-silicon carbide $(3 \mathrm{C}-\mathrm{SiC})$ on silicon dioxide $\left(\mathrm{SiO}_{2}\right)$ by using silicon wet-thermal-oxidation. Experimental data confirmed that $\mathrm{SiO}_{2}$ was successfully formed underneath of $300 \mathrm{~nm}$ width $\mathrm{SiC}$ nanowires, while the properties of $\mathrm{SiC}$ was almost unaffected during the oxidation process. This simple technique will open the pathway to the development of $\mathrm{SiCOI}$ ( $\mathrm{SiC}$ on insulator) based electrical and optical applications.

Keywords: Silicon carbide, SiC on insulator, SiC nanowires, nanowires waveguides, LOCOS, MEMS
\end{abstract}

\section{Introduction}

Wide band gap materials such as diamond like carbon, III-nitride, and silicon carbide have been widely applied in numerous electronic devices, where hostile conditions including high power, high temperature exist [1, 2]. These materials have also been employed in MEMS applications which aim at high frequency and high temperature sensing transducers. Among numerous materials, silicon carbide is a preferable choice owing to its excellent physical properties along with the availability of wafers [3, 4. Nevertheless, the main obstacles which hinder the wide applications of $\mathrm{SiC}$ are the high cost of wafer and low etching rate of $\mathrm{SiC}$ in comparison to $\mathrm{Si}$.

To solve these bottlenecks, cubic silicon carbide thin films, which can be grown on a silicon substrate have been deployed as an excellent platform for MEMS [5, 6, 7, 8. Epitaxial SiC films grown on large scale $\mathrm{Si}$ wafers not only take advantage of low cost Si wafers, but also simplify the fabrication (process) of SiC MEMS. To make SiC devices feasible for applications in harsh environments, electrical insulators

\footnotetext{
* Corresponding author

Email address: hoangphuong.phan@griffithuni.edu.au (Hoang-Phuong Phan)
} 
such as $\mathrm{SiO}_{2}$ are desired to prevent the leakage current from the functional layer ( $\mathrm{SiC}$ ) to the substrate $(\mathrm{Si})$. In addition, the $\mathrm{SiC}$ on $\mathrm{SiO}_{2}$ platform is also of significant interest for optical applications such as $\mathrm{SiC}$ waveguides or photonic crystals since $\mathrm{SiC}$ offers a higher refractive index than $\mathrm{SiO}_{2}$,9, 10, 11. To date, the most common method to form $\mathrm{SiC}$ on insulator is based on wafer bonding. However, wafer bonding typically requires smooth-surface treatment and additional time-consuming steps for the removal of Si. [12, 13, 14, 15.

This letter presents a novel technique to form $\mathrm{SiC}$ on insulator by thermally oxidizing the $\mathrm{Si}$ without the requirements of wafer-bonding and/or silicon removal. The proposed method could pave the way to the development of $\mathrm{SiC}$ based MEMS devices including high temperature sensors, and nanowire waveguides.

\section{Methodology and fabrication process of SiNWs} idea of creating $\mathrm{SiC}$ on $\mathrm{SiO}_{2}$ was motivated by the low oxidation rate of $\mathrm{SiC}$ with respect to $\mathrm{Si}$ [17. Furthermore, when patterning $\mathrm{SiC}$, the $\mathrm{Si}$ substrate was also intentionally etched, forming a $\mathrm{Si}$ sidewall underneath SiC. This sidewall allows the thermal oxidation to occur in the lateral direction, transforming the $\mathrm{Si}$ layer under $\mathrm{SiC}$ into $\mathrm{SiO}_{2}$. It should also be pointed out that, to make $\mathrm{SiC}$ fully is significantly reduced. Consequently, $\mathrm{SiC}$ nano structures such as nanowires are more well suited for the proposed technique than micro structures.

The fabrication process of the $\mathrm{SiC}$ on $\mathrm{SiO}_{2}$ started from a $150 \mathrm{~mm} \mathrm{Si}$ wafer treated with a standard RCA (Radio Corporation of America) process (step 1). A 3C-SiC thin film was then epitaxially grown on the Si wafer using low pressure chemical vapor deposition at $1000^{\circ} \mathrm{C}$ (step 2). The detailed growth process of the $3 \mathrm{C}-\mathrm{SiC}$ can be found elsewhere [18. The thickness of the $\mathrm{SiC}$ layer, measured by

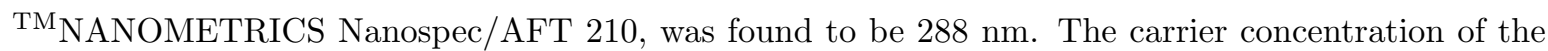
film was $5 \times 10^{18} \mathrm{~cm}^{-3}$ measured by a hot probe technique. Subsequently, $\mathrm{SiC}$ nanowires were formed using FIB (focused ion beam) ${ }^{\mathrm{TM}}$ SII NanoTechnology SMI3050SE (step 3) 19, 20. After the FIB

cutting process, thermal annealing at $500^{\circ} \mathrm{C}$ was performed to eliminate the implanted $\mathrm{Ga}^{+}$ions from 

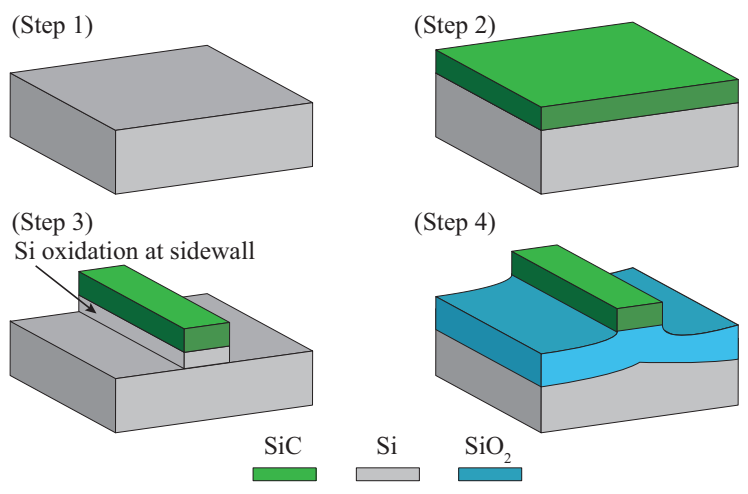

Figure 1: The fabrication process of SiC NWs on insulator

the Si. Finally, the patterned $\mathrm{SiC}$ on $\mathrm{Si}$ samples were wet-oxidized to form $\mathrm{SiC}$ on $\mathrm{SiO}_{2}$. It should be noted that increasing the temperature could significantly reduce the oxidation time; however, the temperature needs to be limited below that used in the LPCVD process in order to prevent unexpected changes in the properties of the $\mathrm{SiC}$ film. Therefore, we carried out the oxidation process at $950^{\circ} \mathrm{C}$, which is below the growth temperature of $3 \mathrm{C}-\mathrm{SiC}\left(1000^{\circ} \mathrm{C}\right)$. The oxidation time for $\mathrm{Si}$ was estimated as follows. Let $t_{o x}$ be the thickness of the grown $\mathrm{SiO}_{2}$, the thickness of the consumed Si layer is $t_{S i}=0.44 \times t_{o x}$. Furthermore, as the oxidation occurs on both sides of the Si sidewall, the actually consumed Si layer must be larger than half of the width of the $\mathrm{SiC}$ nanowires. Therefore, the amount of time required to sufficiently oxidize the $\mathrm{SiC} / \mathrm{Si}$ samples is:

$$
t=\frac{w / 2}{0.44 \times \mu_{T}}
$$

where $w$ and $\mu_{T}$ are the width of the $\mathrm{SiC}$ nanowires, and the oxidation rate of $\mathrm{Si}$ at degree $T$, respectively.

\subsection{Results}

Figure 2 shows the SEM images of SiC nanowire arrays fabricated using FIB. The dimensions of each nanowire were $288 \mathrm{~nm}$ in thickness, $300 \mathrm{~nm}$ in width and $10 \mu \mathrm{m}$ in length. The distance from
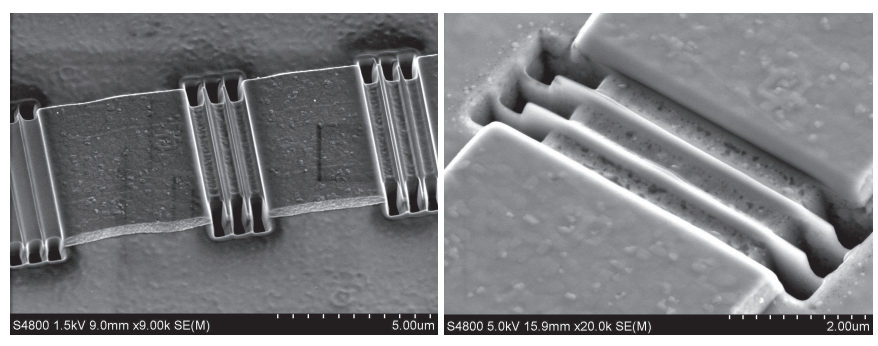

Figure 2: SEM images of SiC nanowires prior to wet-oxidation. 
the top surface of the $\mathrm{SiC}$ film to that of the $\mathrm{Si}$ substrate was also measured to be $455 \mathrm{~nm}$, using ${ }^{\mathrm{TM}}$ Dektak 150. This implies that a Si sidewall with a height of $177 \mathrm{~nm}$ was formed underneath $\mathrm{SiC}$, allowing the subsequent horizontal oxidation.

After the oxidation of $\mathrm{Si}$ at $950^{\circ}$ for 60 minutes, the thickness of the deposited $\mathrm{SiO}_{2}$ layer and the consumed Si layer was obtained through the following experiments. Figure 3(a) plots the thickness of

$\mathrm{SiC}$ before and after the oxidation, and the thickness of the as-deposited $\mathrm{SiO}_{2}$ layer measured using the ${ }^{\mathrm{TM}}$ NANOMETRICS Nanospec/AFT 210. The similarity between the thicknesses of SiC before (288 $\mathrm{nm})$ and after thermal wet-oxidation $(284 \mathrm{~nm})$ indicates the excellent chemical inertness of $3 \mathrm{C}$-SiC with an oxidation rate of below $1 \AA / \mathrm{min}$ at $950^{\circ} \mathrm{C}$. On the other hand, the thickness of the as-oxidized layer was found to be $427 \mathrm{~nm}$, indicating a significant oxidation selectivity between $\mathrm{SiC}$ and $\mathrm{Si}$ of approximately 1:100.

(a)

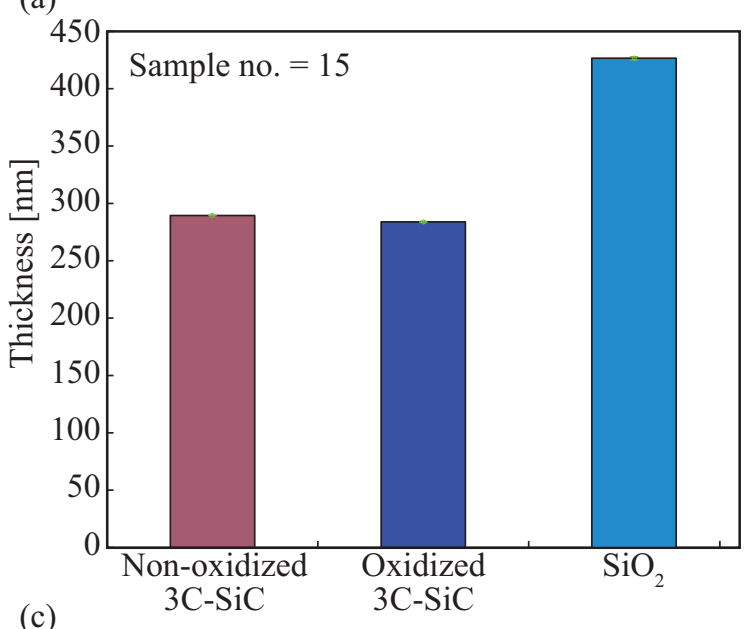

(b)

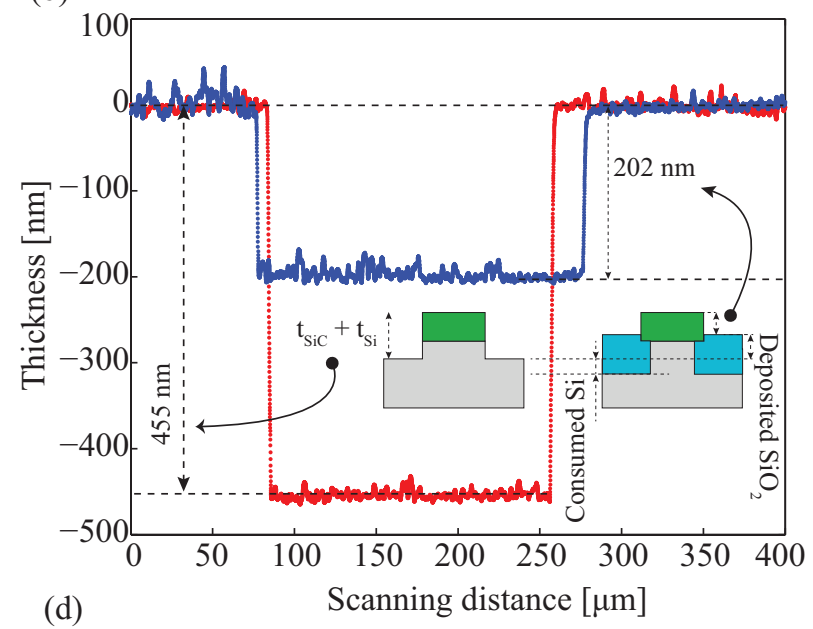

(d)

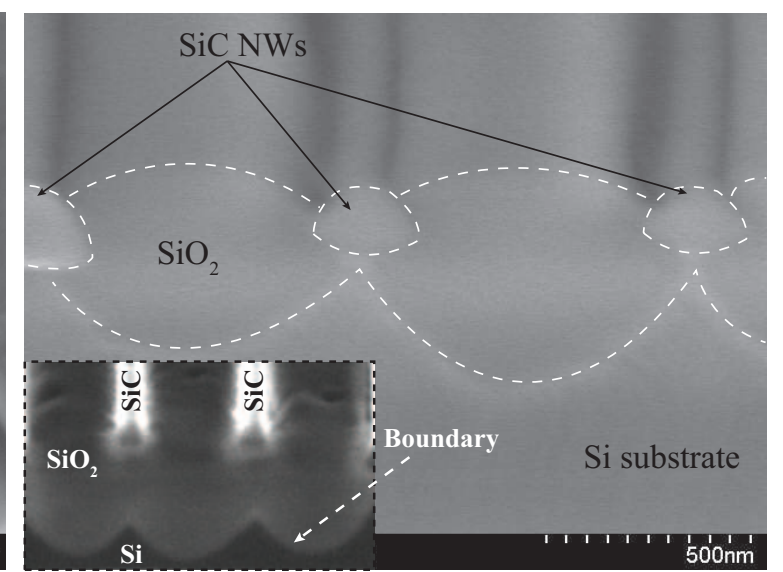

Figure 3: (a) The thickness of $\mathrm{SiC}$ and oxide layers measured using ${ }^{\mathrm{TM}}$ NANOMETRIC Nanospec A210; (b) The thickness of the consumed Si layer measured using ${ }^{\mathrm{TM}}$ Dektak 150; (c) SEM image of SiC nanowires from top view; and (d) Cross sectional $\mathrm{SEM}$ image of the $\mathrm{SiC}$ nanowires (Inset: Observation of a $\mathrm{SiO}_{2} / \mathrm{Si}$ boundary using a FIB-SEM mode). 
(a)

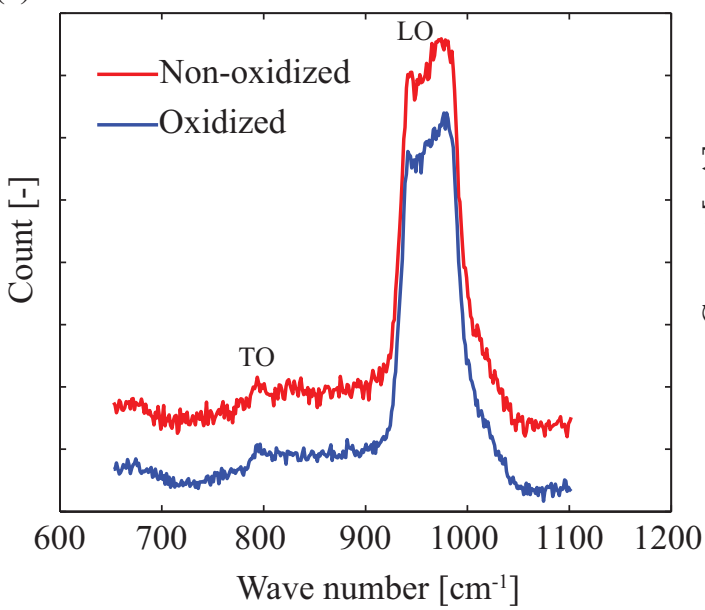

(b)

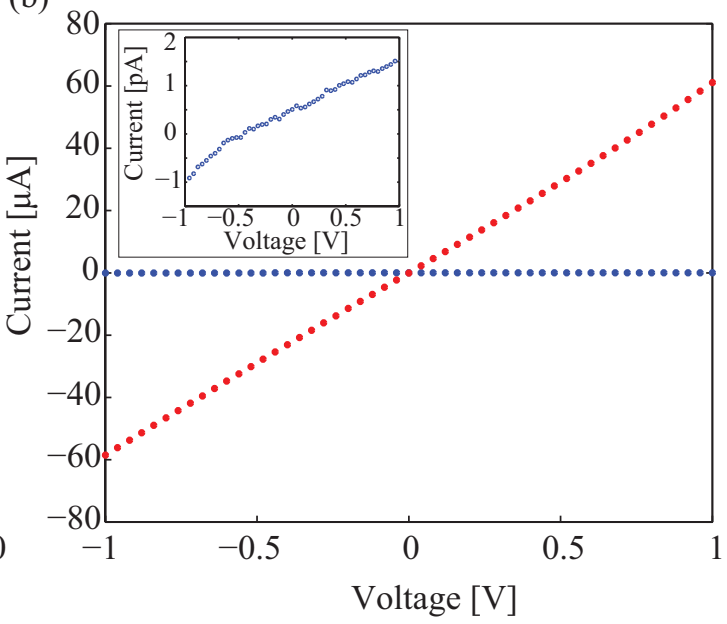

Figure 4: Characterization of the oxidized film; (a) Raman spectroscopy (the intensity was normalized.) (b) CurrentVoltage characteristics of a oxidized $\mathrm{SiC}$ sample and the current leak through the dioxide layer to the Si substrate. Inset: The current leak plotted in pA scale.

The distance between the top surface of the $\mathrm{SiC}$ layer and the as-oxidized $\mathrm{SiO}_{2}$ layer was found to be $202 \mathrm{~nm}$, Fig. 3(b). As a result, the thickness of the additional $\mathrm{SiO}_{2}$ layer deposited on to the Si layer is $t_{t o p, o x}=455-202=253 \mathrm{~nm}$. Consequently, the thickness of the consumed Si layer was $t_{S i}=t_{o x}-t_{t o p, o x}=427-253=174 \mathrm{~nm}$. This result indicates an geometrical ratio between the $\mathrm{SiO}_{2}$ and the consumed Si thicknesses $\left(t_{o x} / t_{S i}\right)$ of 1:0.41, which well fits the model presented in Eq. 1 $\left(t_{o x} / t_{S i}=1: 0.44\right)$. More importantly, the thickness of the consumed Si layer $(174 \mathrm{~nm})$ was larger than half of the width of $\mathrm{SiC}$ nanowires $(150 \mathrm{~nm})$, indicating that the $\mathrm{Si}$ layer under the $\mathrm{SiC}$ nanowires was sufficiently oxidized.

Figure 3(c) presents the SEM image of the as-oxidized $\mathrm{SiC} / \mathrm{Si}$ samples. It can be clearly seen from the top view of SEM that, $\mathrm{SiO}_{2}$ was deposited on the $\mathrm{Si}$ substrate. A cross section of the $\mathrm{SiC}$ NWs was then fabricated using FIB with a small applied power to avoid significant damage, Fig. 3(d). It is evident from the cross sectional SEM image of the $\mathrm{SiC}$ NWs that the $\mathrm{Si}$ underneath of $\mathrm{SiC}$ was successfully oxidized, forming SiCOI, which was consistent with the thickness measurements presented above.

The properties of the oxidized $3 \mathrm{C}-\mathrm{SiC} / \mathrm{Si}$ samples was investigated using the following optical and electrical measurements. The Raman spectroscopy of the oxidized and non-oxidized samples showed almost the same peaks. Accordingly, the transverse optical (TO) and longitudinal optical (LO) phonon modes of the oxidized $\mathrm{SiC} / \mathrm{Si}$ samples were observed at $794 \mathrm{~cm}^{-1}$ and $970 \mathrm{~cm}^{-1}$, respectively. This result indicates that the oxidized film remained crystalline $3 \mathrm{C}-\mathrm{SiC}$. The sheet resistance of the oxidized $\mathrm{SiC}$ was found to be $4 \mathrm{k} \Omega$ /square using ${ }^{\mathrm{TM}}$ Agilent B1505A, Fig. 4 . This indicates that the highly 
doped $\mathrm{SiC}$ exhibited good electrical conductivity after oxidation. The current leak through the $\mathrm{SiO}_{2}$ layer to the Si substrate was measured by sweeping a voltage from $-1 \mathrm{~V}$ to $1 \mathrm{~V}$, showing an ultra-small leakage of below $2 \mathrm{pA}$ at $\pm 1 \mathrm{~V}$. This result demonstrates that the wet oxidized $\mathrm{SiO}_{2}$ layer can function as an excellent electrical-insulator for $\mathrm{SiC}$ devices. Furthermore, since the refractive index of $3 \mathrm{C}-\mathrm{SiC}$ is 2.65, which is much larger than that of the $\mathrm{SiO}_{2}$ substrate (1.55), the developed 3C-SiC nanowires on dioxide should be applicable for optical waveguide.

\section{Conclusion}

This work presents a novel fabrication process to form $\mathrm{SiC}$ on insulator using silicon thermal oxidation. Our experimental results confirmed that it is possible to form the $\mathrm{SiO}_{2}$ layer underneath of $\mathrm{SiC}$ nanowires without the requirements of wafer bonding owing to the chemical inertness of $\mathrm{SiC}$ and the high oxidation rate of $\mathrm{Si}$ at high temperature. The excellent crystallinity and electrical conduction of $\mathrm{SiC}$ along with the negligible current leak through $\mathrm{SiO}_{2}$ indicates the feasibility of developing $\mathrm{SiCOI}$ based devices for a wide range of electronics and optical applications.

\section{Acknowledgment}

This work was partially funded by the linkage grant (LP150100153) from the Australian Research Council (ARC). This work was supported by the Queensland node of the Australian National Fabrication Facility, a company established under the National Collaborative Research Infrastructure Strategy to provide nano and micro-fabrication facilities for Australia's researchers.

\section{Reference}

[1] H.-P. Phan, D. V. Dao, S. Dimitrijev, K. Nakamura, N.-T. Nguyen, "The piezoresistive effect of SiC for MEMS sensors at high temperatures: A review," J. Microelectromech. Syst., 24(6), 1663-1677, 2015.

[2] D. G. Senesky, B. Jamshidi, K. B. Cheng, and A. P. Pisano, "Harsh environment silicon carbide sensors for health and performance monitoring of aerospace systems: A review," IEEE Sensors J., $9(11), 1472-1478,2009$.

[3] R. Maboudian, C. Carraro, D. G. Senesky, and C. S. Roper, "Advances in silicon carbide science and technology at the micro- and nanoscales," J. Vac. Sci. Technol. A, 31(5), 050805, 2013.

[4] C. Ferraro, , E. Garcia-Tunon, and E. Saiz, "A silicon carbide lollipop," Materialstoday, 18(2), $117-118,2015$. 
[5] H.-P. Phan, A. Qamar, D. V. Dao, T. Dinh, L. Wang, J. Han, P. Tanner, S. Dimitrijev, N.-T. Nguyen, "Orientation dependence of the pseudo-Hall effect in p-type 3C-SiC four-terminal devices under mechanical stress," RSC Adv., 5, 56377-56381, 2015.

[6] J. S. Shor, D. Goldstein, and A. D. Kurtz, "Characterization of n-type $\beta$-SiC as a piezoresistor," IEEE Trans. Electron Devices, 40(6), 1093-1099, 1993.

[7] D. V. Dao, H.-P. Phan, A. Qamar, T. Dinh, "Piezoresistive effect of p-type single crystalline 3C-SiC on (111) plane," RSC Adv., 6, 21302-21307, 2016.

[8] C.-H. Wu, C. A. Zorman, and M. Mehregany, "Fabrication and testing of bulk micromachined silicon carbide piezoresistive pressure sensors for high temperature applications," IEEE Sensors J., 62, 316-324, Apr. 2006.

[9] W. Du, and F. Zhao, "Silicon carbide based surface plasmon resonance waveguide sensor with a bimetallic layer for improved sensitivity," Mater. Lett., 186(1), 224-226, Jan. 2017.

[10] G. Pandraud, B. Neira, P.M. Sarro, "PECVD SiC-SiO ${ }_{2}-\mathrm{SiC}$ horizontal slot waveguides for sensing photonics devices," IEEE Sensors Conf., 975-978, 2010.

[11] D. Ma, Z. Han, Q. Du, J. Hu, L. Kimerling,A. Agarwal, and D. T. Tan, "SiC-on-insulator on-chip photonic sensor in a radiative environment," IEEE Sensor Conf., 1-3, 2016.

[12] G.-S. Chung, and R. Maboudian, "Bonding characteristics of 3C-SiC wafers with hydrofluoric acid for high-temperature MEMS applications," Sens. Actuators A, Phys., 119(2), 599-604, Apr. 2005.

[13] K. Vinod, C.A. Zorman, A. A. Yasseen, and M. Mehregany, "Fabrication of Low Defect Density 3C-SiC on $\mathrm{SiO} 2$ Structures Using Wafer Bonding Techniques," J. Electronic Mater., 27(3), 17-20, 1998.

[14] Tudryn et al. Anodic bonding of Silicon carbide to glass, US Patent, US 2005/0072189 A1, Apr. 2005.

[15] F. Mu, K. Iguchi, H. Nakazawa, Y. Takahashi, M. Fujino, R. He, and T. Suga, "A comparison study: Direct wafer bonding of $\mathrm{SiC}-\mathrm{SiC}$ by standard surface-activated bonding and modified surface-activated bonding with Si-containing Ar ion beam," Appl. Phys. Exp., 9, 081302, 2016.

[16] N. Sherwood-Droz, A. Gondarenko, and M. Lipson, "Oxidized Silicon-On-Insulator (OxSOI) from bulk silicon: a new photonic platform," Opt. Exp., 18(6), 5785. 
[17] E. J. Opila, "Variation of the Oxidation Rate of Silicon Carbide withWater-Vapor Pressure," J. Am. Ceram. Soc., 82(3), 625-36, 1999.

[18] H.-P. Phan, T. Dinh, T. Kozeki, A. Qamar, T. Namazu, S. Dimitrijev, N.-T. Nguyen, and D. V. Dao, "Piezoresistive effect in p-type 3C-SiC at high temperatures characterized using Joule heating," Scientific Reports, 6, 28499, 2016.

[19] H.-P. Phan, T. Kozeki, T. Dinh, T. Fujii, A. Qamar, Y. Zhu, T. Namazu, N.-T. Nguyen, and D. V. Dao, "Piezoresistive effect of p-type silicon nanowires fabricated by a top-down process using FIB implantation and wet etching," RSC Adv., 5(), 82121-82126, 2015.

[20] T. Dinh, H.-P. Phan, T. Kozeki, A. Qamar, T. Fujii, T. Namazu, N.-T. Nguyen, and D. V. Dao, "High thermosensitivity of silicon nanowires induced by amorphization," Mater. Lett., 177, 80-84, 2016. 